\title{
Unconditioned and conditioned responses to colour in the predatory coccinellid, Harmonia axyridis (Coleoptera: Coccinellidae)
}

\author{
EDWARD B. MONDOR and JESSIE L. WARREN
}

Behavioural Ecology Research Group, Department of Biological Sciences, Simon Fraser University, Burnaby, British Columbia, Canada V5A 1S6; e-mail: emondor@sfu.ca

Keywords. Harmonia axyridis, ladybird, Coccinellidae, foraging, colour, conditioning

\begin{abstract}
We determined if mature ladybirds use colour to initially find suitable host plants. We also determined whether ladybird beetles are capable of associating characteristics such as colour with the presence of prey. Here, we show that the multicoloured Asian ladybird beetle, Harmonia axyridis, has a differential response to yellow compared to green colours. Naive ladybirds, of both sexes, make significantly more visits and spend more time on yellow vs. green coloured pillars. After pairing yellow and green colours with the presence or absence of aphid prey, ladybirds alter their foraging behaviour. Beetles conditioned to having food on both pillar colours exhibited the same responses as naive beetles, while beetles conditioned to only yellow or green pillars did not exhibit a preference for visiting or spending time on different colours. However, there was a trend towards females spending more time on pillar colours on which they received reinforcement, and males spending more time foraging on colours opposite to that which they were reinforced. Thus, $H$. axyridis is capable of responding to cues such as colour, and its foraging behaviour can be altered as a result of prior experience.
\end{abstract}

\section{INTRODUCTION}

Coccinellids are key aphid predators under natural conditions (Hagen, 1962). Adult beetles forage both within and among individual host plants and host plant species in order to find aphid colonies as, even in the absence of natural enemies, numbers of aphids fluctuate on different host plants during the season (Dixon, 1985). But despite being significant bio-control agents of aphids (Frazer \& Gilbert, 1976), relatively little is known about the cues used by adult coccinellids when searching for aphid infested plants (Ferran \& Dixon, 1993).

It was originally believed that adult ladybirds searched at random, even though they possessed an extensive array of sensory receptors (Murdie, 1971). However, it is now clear that adult coccinellids do use various cues to initially locate prey habitat. For example, adult ladybirds are attracted to and spend more time in areas that have prey odour (Colburn \& Asquith, 1970; Obata, 1986; Hattingh \& Samways, 1995; Mondor \& Roitberg, in press). Adult beetles also show preference for visual cues such as: distant vs. close objects, a simulated horizon with a tree line vs. a flat one, vertical parallel lines vs. horizontal ones, and simple ovate leaves vs. compound bipinnate or square leaves (Collett, 1988; Hattingh \& Samways, 1995). Another yet unexplored visual cue that may provide adult beetles with information on aphid presence is colour.

Ladybirds have three types of visual receptors: UV, blue, and green receptors that allow them to respond to wavelengths from 310-600 nm (Agee et al., 1990; Lin, 1993). Some ladybird species preferentially attack aphids that contrast with their background (Harmon et al., 1998), indicating colour perception. On a larger scale, young plants and stressed plants, both of which are more susceptible to aphid infestation, often take on more yellowish hues than healthy, green plants (Lorenzetti et al., 1997). Thus, the colour of the host plant may provide ladybirds with information about aphid infestation. It is also unclear how prior experience influences coccinellid foraging behaviour (Ferran \& Dixon, 1993). In ladybirds, diet preference is altered as a result of experience (Houck, 1986; Ettifouri \& Ferran, 1993). In a natural environment responding to colour may be important as different ages, and particularly different species, of plants (both aphid infested and uninfested) take on different hues in the green - yellow wavelengths between 500-600 nm. For example, uninfested pea plants may appear more yellowish than heavily infested bean plants. Thus, if predatory coccinellids alter their behaviour as a result of prior experience, it could result in significant changes in predator efficacy (Kamil, 1983).

Using the multicoloured Asian lady beetle, Harmonia axyridis Pallas, we investigated whether colour is used to locate pea aphid, Acyrthosiphon pisum, colonies, by allowing ladybirds to search different colours of pillars. We also addressed whether predatory coccinellids alter their behaviour after finding prey only on certain pillar colours

\section{MATERIALS AND METHODS}

\section{Insects and Plants}

Pea aphids, A. pisum, were collected from sweet pea, Lathyrus odoratus "Cuthbertson" in Burnaby, British Columbia. Aphids were reared in the laboratory on broad bean plants, Vicia faba "Broad Windsor", potted in standard garden soil. Bean plants used for colony maintenance and for the experiments were grown at $22-28^{\circ} \mathrm{C}, 25-75 \% \mathrm{rh}$, and $16 \mathrm{~L}: 8 \mathrm{D}$. Aphids were maintained at $22-24^{\circ} \mathrm{C}, 50 \pm 20 \% \mathrm{rh}$, and $16 \mathrm{~L}: 8 \mathrm{D}$.

$H$. axyridis were collected as adults from several different locations in Burnaby, British Columbia. They were reared in the 
laboratory on pea aphids and banana at $22-24^{\circ} \mathrm{C}, 50 \stackrel{ \pm}{=} 20 \% \mathrm{rh}$, and $16 \mathrm{~L}: 8 \mathrm{D}$. Adults used for the experiments were not more than two generations from wild collected stock.

\section{Experiment 1 - Unconditioned responses to yellow vs. green pillars}

In this experiment we examined whether $H$. axyridis have a naive preference for yellow vs. green colour. Adult ladybirds $(n=13)$ were removed from rearing cages, placed in individual Petri dishes, and held without food for $24 \mathrm{~h}$. After this time, a single ladybird beetle, selected at random, was placed inside a Plexiglas cage $(32 \mathrm{~h} \times 32 \mathrm{w} \times 42 \mathrm{lcm})$. Inside the cage was a green and a yellow pillar presented simultaneously, both made of construction paper, measuring $13 \mathrm{~cm}$ in height $\times 8 \mathrm{~cm}$ in diameter. These pillars were separated by approximately $20 \mathrm{~cm}$ inside the Plexiglas cage. These pillars both reflected a significant amount of light, as measured by a Cary 14 reflectance spectrophotometer, in the range of hues visible to ladybird beetles, 310-600 nm (Fig. 1) (Agee et al., 1990; Lin, 1993).

An individual ladybird beetle was placed between the 2 pillars and allowed to search for $15 \mathrm{~min}$. We recorded the number of visits to, and the time spent searching on, each pillar for the duration of the searching interval. The cage was then wiped ou with a damp cloth, the location of the pillars switched, and testing of the next ladybird beetle commenced.

\section{Experiment 2 - Conditioned responses to yellow vs. green pillars}

This experiment determined whether ladybirds alter their behaviour after prior experience with certain pillar colours and the presence of aphid prey. Adult $H$. axyridis were removed from rearing cages and placed, in groups of 20, in Plexiglas cages, the same dimensions as the bioassay cage. Inside each cage was a yellow and a green pillar, (see Experiment 1) with a Petri dish on the top of each pillar. Inside one cage, food was given on the top of both pillars (control), in a second cage food

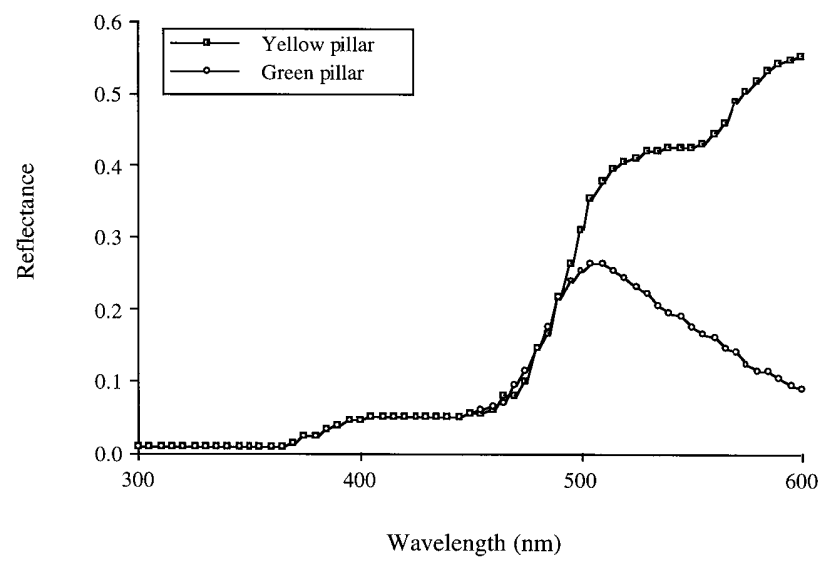

Fig. 1. Spectral reflectance of yellow and green pillars used in the experiments, as compared to a black control.

was only given on the top of the yellow pillar (conditioned to yellow), and in the third cage food was only given on the top of the green pillar (conditioned to green). Food consisted of aphids (that had been previously frozen) and slices of ripe banana, and was replaced every second day for the duration of the experiment. In order to get the food, ladybird beetles had to crawl to the top of the correct coloured pillar.

After three weeks, ladybird beetles $(n=39 ; n=13$ for each treatment) were removed from the cages, placed in individual Petri dishes, and held without food for $24 \mathrm{~h}$. After this time, an individual ladybird beetle, selected at random, was placed inside a Plexiglas cage with a yellow and a green pillar, devoid of food. An individual ladybird beetle was placed between the two pillars and allowed to search for $15 \mathrm{~min}$. We recorded the number of visits, and the time spent searching, on each colour of pillar for the duration of the searching interval. The cage was then wiped out with a damp cloth, the location of the pillars switched, and testing of the next ladybird beetle commenced.

\section{Statistical analyses}

Statistical analyses for all experiments were conducted using JMP IN (SAS Institute Inc., 1997). For both analyses, testing sequence of the ladybirds was analyzed as a covariate, to determine whether beetles responded to the presence of previous searching beetles on the pillars. For Experiment 1 testing sequence was not a significant covariate, thus one factor repeated measures analyses of variance were conducted. The main factor in the analyses was sex of ladybird (male vs. female), and the repeated measure was the colour of pillar (yellow vs. green). A repeated measures design was used due to the lack of independence between choices, within a choice test (Sokal \& Rohlf, 1981; Zar, 1984). The t-test for paired comparisons is an alternative method of analysis (Sokal \& Rohlf, 1981), however repeated measures designs allow us to add multiple main factors to the analysis. A separate analysis was conducted for both the number of visits to each colour of pillar $\left(x^{\prime}=(\sqrt{ } x)+\right.$ $(\sqrt{ } \mathrm{x}+1))$, and the time spent searching each pillar $\left(\mathrm{x}^{\prime}=\right.$ $\left.\log _{10} \mathrm{x}+1\right)$.

For Experiment 2, testing sequence was a significant covariate, thus two factor repeated measures analyses of covariance were conducted, with sex of ladybird (male vs. female) and conditioning stimulus (conditioned to both colours vs. conditioned to yellow vs. conditioned to green) as main factors. The repeated measure was again pillar colour, with separate analyses being conducted for both the number of visits to each colour of pillar $\left(x^{\prime}=(\sqrt{x})+(\sqrt{x}+1)\right)$, and the time spent searching each pillar $\left(x^{\prime}=\log _{10} x+1\right)$. If ladybirds do alter their foraging behaviour after pairing colour with prey availability, we would expect to see significant interactions between our main factors and pillar colour.

\section{RESULTS}

\section{Experiment 1 - Unconditioned responses to yellow vs. green pillars}

There was no significant difference between the number of visits made by male and female beetles to pillars (male $-0.833, \mathrm{SE}=0.477$ vs. female $-0.650, \mathrm{SE}=$ $0.131 ; F_{1,11}=0.0271, P=0.872$ ). However, more visits were made by beetles to yellow pillars than to green pillars (yellow $-1.077, \mathrm{SE}=0.211$ vs. green $-0.308, \mathrm{SE}=$ $\left.0.133 ; \mathrm{F}_{1,11}=11.585, \mathrm{P}=0.0059\right)$. As there was no significant interaction, both male and female beetles preferred yellow pillars $\left(F_{1,11}=2.751, P=0.125\right)$ (Fig. $\left.2 a\right)$.

Male and female ladybirds spent similar amounts of time on the pillars (male $-50.67, \mathrm{SE}=23.48$ vs. female $\left.61.60, \mathrm{SE}=36.41 ; \mathrm{F}_{1,11}=0.0733, \mathrm{P}=0.792\right)$. More time was spent by beetles on yellow vs. green pillars (yellow 113.23, $\mathrm{SE}=53.32$ vs. green $-4.92, \mathrm{SE}=2.56 ; \mathrm{F}_{1,11}=$ $13.340, \mathrm{P}=0.0038$ ). As there was no significant interaction, both male and female beetles spent more time on yellow pillars $\left(\mathrm{F}_{1,11}=1.724, \mathrm{P}=0.216\right)$ (Fig. $\left.2 \mathrm{~b}\right)$. 
(a)

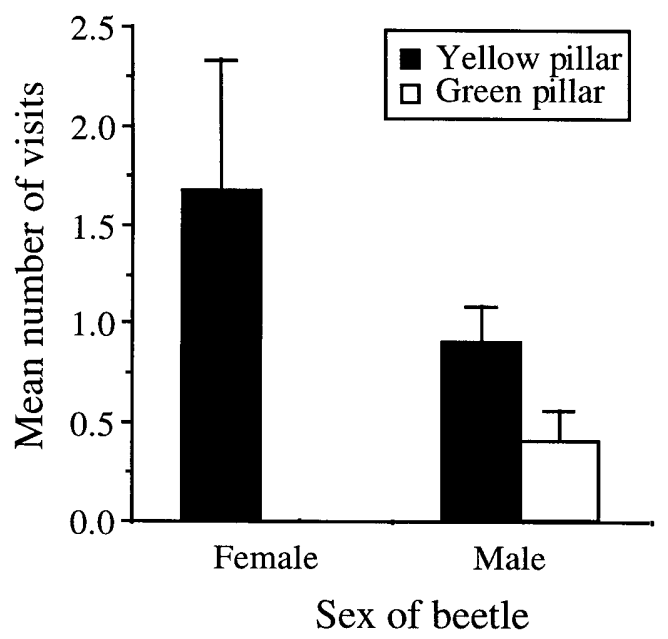

(b)

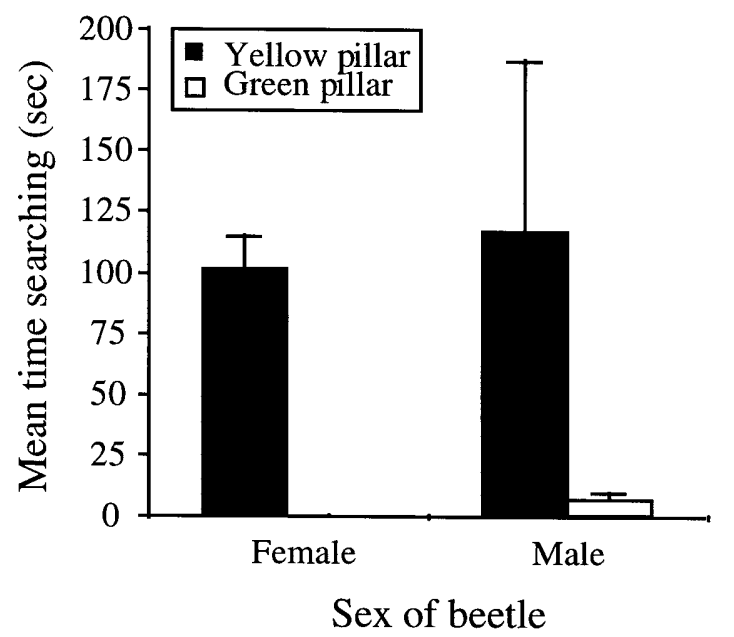

Fig. 2. (a) Mean number ( $\pm 1 \mathrm{SE}$ ) of visits and (b) mean time ( $\mathrm{sec} \pm 1 \mathrm{SE}$ ) spent, by naive $H$. axyridis on yellow vs. green coloured pillars during 15 minute search intervals.

\section{Experiment 2 - Conditioned responses to yellow vs. green pillars}

Neither conditioning stimulus (both colours $-1.27, \mathrm{SE}$ $=0.29$ vs. green $-0.46, \mathrm{SE}=0.19$ vs. yellow $-0.50, \mathrm{SE}=$ $0.13 ; F_{2,29}=2.29, \mathrm{P}=0.119$ ), nor sex of beetle (male $0.91, \mathrm{SE}=0.21$ vs. female $-0.39, \mathrm{SE}=0.094 ; \mathrm{F}_{1,29}=$ $0.0173, \mathrm{P}=0.896$ ) resulted in different numbers of visits to pillars. There was no conditioning stimulus by sex interaction $\left(\mathrm{F}_{2,29}=0.146, \mathrm{P}=0.865\right)$, indicating that under the different conditioning stimuli male and female beetles visit similar numbers of pillars, in general. Testing sequence was a significant covariate $\left(\mathrm{F}_{1,29}=6.804, \mathrm{P}=\right.$ $0.014)$, as beetles tested earlier in the experiment tended to make more visits to pillars than beetles tested later in the experiment. However, conditioning significantly altered beetles responses to colours, as beetles subjected to different conditioning stimuli did not all prefer yellow as compared to green pillars $\left(\mathrm{F}_{2,29}=3.80, \mathrm{P}=0.034\right)$ (Fig. 3a). Males and females visited the two pillar colours in the same proportions $\left(\mathrm{F}_{1,29}=0.476, \mathrm{P}=0.496\right)$, and there was no sex by conditioning stimuli by pillar colour interaction $\left(F_{2,29}=2.015, P=0.152\right)$ (Fig. 3a). There also was no testing sequence by pillar colour interaction $\left(\mathrm{F}_{1,29}=0.358, \mathrm{P}=0.554\right)$, indicating that beetles exhibited consistent preferences for pillar colours throughout the experiment.

Beetles subjected to different conditioning stimuli spent different amounts of time searching pillars (both colours $-154.65, \mathrm{SE}=32.14$ vs. green $-58.00, \mathrm{SE}=33.93$ vs. yellow $-63.65, \mathrm{SE}=24.57 ; \mathrm{F}_{2,29}=3.57, \mathrm{P}=0.041$ ). Male and female beetles did not spend different amounts of time on pillars (male $-83.79, \mathrm{SE}=21.08$ vs. female 88.39, $\left.\mathrm{SE}=35.84 ; \mathrm{F}_{1,29}=0.794, \mathrm{P}=0.380\right)$. After being exposed to the different conditioning stimuli, male and female beetles spent similar amounts of time on pillars $\left(\mathrm{F}_{2,29}=0.487, \mathrm{P}=0.619\right)$. Testing sequence was a significant covariate $\left(\mathrm{F}_{1,29}=10.096, \mathrm{P}=0.0035\right)$, as beetles tested earlier in the experiment tended to spend more time on pillars than beetles tested later in the experiment. Once again, conditioning significantly altered beetles responses to colours, as beetles subjected to different conditioning stimuli did not all spend more time on yellow as compared to green pillars $\left(\mathrm{F}_{2,29}=6.458, \mathrm{P}=0.0048\right)$ (Fig. 3b). Males and females spent similar amounts of time on the two pillar colours $\left(\mathrm{F}_{1,29}=1.162, \mathrm{P}=0.290\right)$. There was a trend towards a sex by conditioning stimuli by pillar colour interaction $\left(\mathrm{F}_{2,29}=2.930, \mathrm{P}=0.069\right)$ (Fig. 3b). There also was no testing sequence by pillar colour interaction $\left(\mathrm{F}_{1,29}=0.047, \mathrm{P}=0.830\right)$, indicating that beetles exhibited consistent preferences for pillar colours throughout the experiment.

\section{CONCLUSIONS AND DISCUSSION}

Ladybird beetles do not search plants randomly for aphid prey. Both sexes of naive $H$. axyridis, are preferentially attracted to and spend more time on yellow compared to green pillars, perhaps resembling young or stressed plants, both of which aphids may be found upon in greater numbers (Lorenzetti et al., 1997). It is important to note that our pillar colours differed in not only hue, but also intensity. While intensity may be an important component of attraction, wavelength itself is extremely important, at least for captures on field traps (Mensah, 1997). Coccinellids under natural conditions would be exposed to a wide range of host plant colours. Further experimentation is required to determine the attractiveness of both hue and intensity. Once attractiveness to colour is understood, it may be possible to manipulate natural enemy behaviour using these stimuli (Udayagiri, 1997).

Preferential attraction to yellow is not a fixed response as, through pairing the presence of food with yellow or green colour, we were able to significantly alter the ladybird beetles foraging behaviour. Beetles that were given food on both pillar colours still preferred yellow pillars, perhaps reinforcing the beetles naive responses. Beetles conditioned to yellow or green pillars though, showed altered behaviour in that they both visited and spent similar amounts of time on both colours. It is uncertain why yellow conditioned beetles did not show similar, or 
(a)

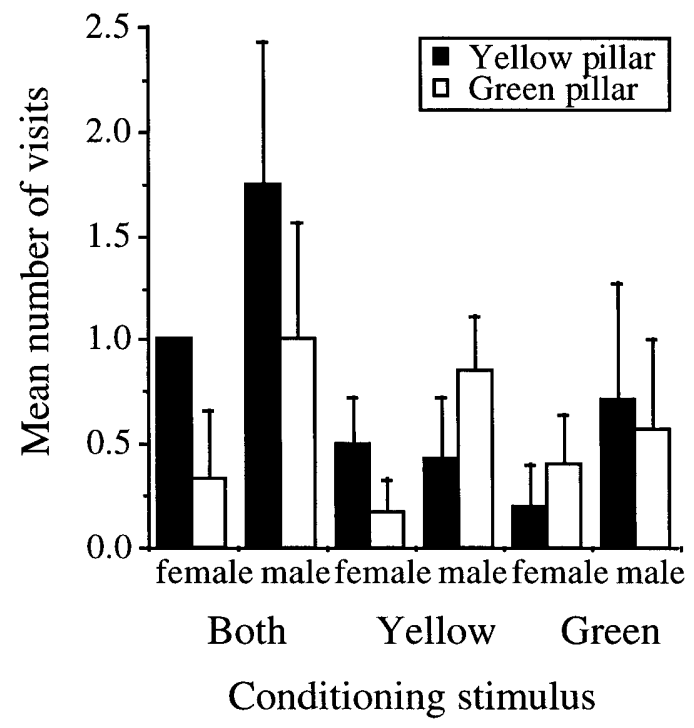

(b)

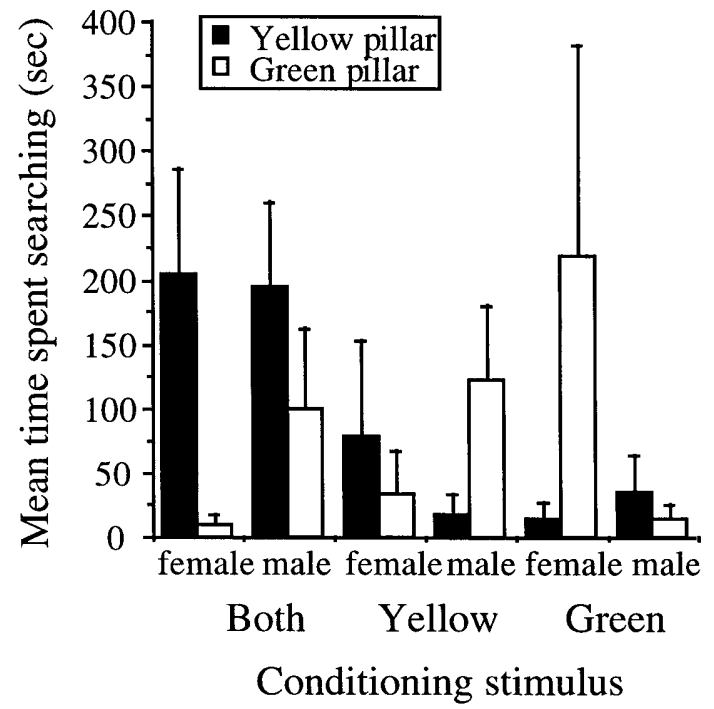

Fig. 3. (a) Mean number ( $\pm 1 \mathrm{SE}$ ) of visits and (b) mean time ( $\sec \pm 1 \mathrm{SE}$ ) spent, by conditioned $H$. axyridis on yellow vs. green coloured pillars during 15 minute search intervals.

even stronger, responses to yellow pillars than naive beetles. Male and female beetles made similar numbers of visits to pillars after exposure to different conditioning stimuli. However, there was a trend towards females spending more time on pillar colours on which they received reinforcement, and males spending more time foraging on colours opposite to that which they were reinforced.

Nutritional differences between male and female beetles may account for the difference in searching behaviour. Male beetles consume very few aphids compared to female beetles (Smith, 1965; Hemptinne et al., 1996). Thus, it is possible that $24 \mathrm{~h}$ of starvation did not provide the same amount of hunger in male beetles compared to that in female beetles. Further, Obata (1997) has observed that male $H$. axyridis encountering an aphid colony will often not feed, but continue walking. Thus, male beetles may be more focused on mate searching rather than food searching.

One caveat, it was clear from our experiment that beetles respond to the presence of previously searching beetles, as ladybirds tended to make fewer visits and spend less time on pillars the later in the experiment they were tested; much like ladybird larvae (Marks, 1977). By analyzing testing sequence as a covariate, we were able to substantially reduce its associated error from our experiment, as it was similar under all experimental treatments. As a result, by incorporating testing sequence into our analyses, conditioning effects were even more apparent than if we had not taken this variable into account. Future studies, however, should a priori control for beetle responses to the presence of other beetles, when searching for prey.

Thus, many questions remain unanswered about the response of ladybirds to host plant colours, and the altered responses after reinforcement. For instance, how does attraction to colour function in a heterogeneous habitat, where a variety of cues are present? More research is required to understand predatory coccinellid search behaviour to augment biological control efforts.

ACKNOWLEDGEMENTS. We would like to thank L. Takahashi for helping to maintain aphid and ladybird beetle colonies. We also thank B. Roitberg, R. Sargent, J. Tyerman, and several anonymous reviewers for comments on previous versions of this manuscript. Funding for this project was provided by a Natural Sciences and Engineering Research Council of Canada (NSERC) PGS-B award to EBM.

\section{REFERENCES}

Agee H.R., Mitchell E.R. \& Flanders R.V. 1990: Spectral sensitivity of the compound eye of Coccinella septempunctata (Coleoptera: Coccinellidae). Ann. Entomol. Soc. Am. 83: 817-819.

Colburn R. \& Asquith D. 1970: A cage used to study the finding of a host by the ladybird beetle, Stethorus punctum. $J$. Econ. Entomol. 63: 1376-1377.

COLLETT T.S. 1988: How ladybirds approach nearby stalks: a study of visual selectivity and attention. J. Comp. Physiol. (A) 163: $355-363$.

Dixon A.F.G. 1985: Aphid Ecology. Blackie, Glasgow, 157 pp.

EtTifouri M. \& Ferran A. 1993: Influence of larval rearing diet on the intensive searching behaviour of Harmonia axyridis (Col.: Coccinellidae) larvae. Entomophaga 38: 51-59.

Ferran A. \& Dixon A.F.G. 1993: Foraging behaviour of ladybird larvae (Coleoptera: Coccinellidae). Eur. J. Entomol. 90: 383-402.

Frazer B.D. \& Gilbert N. 1976: Coccinellids and aphids: A quantitative study of the impact of adult ladybirds (Coleoptera: Coccinellidae) preying on field populations of pea aphids (Homoptera: Aphididae). J. Entomol. Soc. Br. Colum. 73: $3-56$.

HAGEN K.S. 1962: Biology and ecology of predaceous Coccinellidae. Annu. Rev. Entomol. 7: 289-326.

Harmon J., Losey J.E. \& Ives A.R. 1998: The role of vision and colour in the close proximity foraging behavior of four coccinellid species. Oecologia 115: 287-292. 
Hattingh V. \& Samways M.J. 1995: Visual and olfactory location of biotopes, prey patches, and individual prey by the ladybeetle Chilocorus nigritus. Entomol. Exp. Appl. 75: $87-98$.

Hemptinne J-L., Dixon A.F.G. \& Lognay G. 1996: Searching behaviour and mate recognition by males of the two-spot ladybird beetle, Adalia bipunctata. Ecol. Entomol. 21: $165-170$.

Houck M.A. 1986: Prey preference in Stethorus punctum (Coleoptera: Coccinellidae). Envir. Entomol. 15: 967-970.

KAMIL A.C. 1983: Optimal foraging theory and the psychology of learning. Am. Zool. 23: 291-302.

LiN J-T. 1993: Identification of photoreceptor locations in the compound eye of Coccinella septempunctata Linnaeus (Coleoptera: Coccinellidae). J. Insect Physiol. 39: 555-562.

Lorenzetti F., Arnason J.T., Philogene B.J.R. \& Hamilton R.I. 1997: Evidence for spatial niche partitioning in predaceous aphidophaga: Use of plant colour as a cue. Entomophaga 42: 49-56.

MARKs R.J. 1977: Laboratory studies of plant searching behaviour by Coccinella septempunctata. Bull. Entomol. Res. 67: 235-241.

MensaH R.K. 1997: Yellow traps can be used to monitor populations of Coccinella transversalis (F.) and Adalia bipunctata (L.) (Coleoptera: Coccinellidae) in cotton crops. Aust. J. Entomol. 36: 377-381.

Mondor E.B. \& RortBerg B.D. Has the attraction of predatory coccinellids to cornicle fluid constrained aphid alarm signaling behaviour? J. Insect Behav. (in press).
MURDIE G. 1971: Simulation on the effects of predator/parasite models on prey/host spatial distribution. In Patil G.P., Pielou E.C. \& Waters W.E. (eds): Statistical Ecology 1. Pennsylvania State University Press, Harrisburg, pp. 215-223.

OвAтA S. 1986: Mechanisms of prey finding in the aphidophagous ladybird beetle, Harmonia axyridis (Coleoptera: Coccinellidae). Entomophaga 31: 303-311.

Oвата S. 1997: The influence of aphids on the behaviour of adults of the ladybird beetle, Harmonia axyridis (Col.: Coccinellidae). Entomophaga 42: 103-106.

SAS Institute Inc. 1997. JMP IN - version 3.2.1. SAS Campus Drive, Cary, NC 27513.

SMITH B.C. 1965: Effects of food on longevity, fecundity, and development of adult coccinellids (Coleoptera: Coccinellidae). Can. Entomol. 97: 910-919.

SOKal R.R. \& RohlF F.J. 1981: Biometry - Second Edition. W.H. Freeman and Company, New York, $859 \mathrm{pp}$.

UdayagrR S., Mason C.E. \& Pesek JR. J.D. 1997: Coleomegilla maculata, Coccinella septempunctata (Coleoptera: Coccinellidae), Chrysoperla carnea (Neuroptera: Chrysopidae), and Macrocentrus grandii (Hymenoptera: Braconidae) trapped on coloured sticky traps in corn habitats. Envir. Entomol. 26: 983-988.

ZAR J.H. 1984: Biostatistical Analysis. Prentice-Hall, Englewood Cliffs, New Jersey, 718 pp.

Received January 6, 2000; accepted June 5, 2000 